\title{
PARENT AND CHILDREN'S CHARACTERISTICS BY CUSTODY TYPE: A HIGH CONFLICT SAMPLE
}

\author{
Marta Herrero $^{1}$, Ana Martínez-Pampliega ${ }^{1}$, Irati Alvarez ${ }^{1}$, Mireia Sanz-Vázquez ${ }^{2}$, \\ Susana Cormenzana ${ }^{1}, \&$ Susana Corral ${ }^{1}$ \\ ${ }^{1}$ Department of Psychology and Education, Deusto University (Spain) \\ ${ }^{2}$ Department of Psychopedagogy, Begoñako Andra Mari (Spain)
}

\begin{abstract}
Divorced parents face challenges that might lead to detrimental psychological difficulties to their own and their children. These challenges are even higher in high conflict interparental conditions. In this context, there are differential positions about the adequacy of shared or exclusive custody based on their influence on parents' divorce adaptation. The goal of this study is to examine the psychological characteristics of parents and children in families with high interparental conflict by custody type. On this goal, a cross-sectional study was developed in Spanish public centers that support divorced parents with high interparental conflict. The study sample was 254 parents (39\% fathers, $61 \%$ mothers) who ranged between 23 to 63 years old. Parents who participated had mainly exclusive custody $(80 \%)$. We developed mean comparisons to test the differences between parents who had shared or exclusive custody. Results indicated that children of both groups had similar levels of somatization, anxiety/depression and aggressive symptoms. As well, parents who had shared or exclusive custody had similar parenting styles and general levels of psychological symptoms. Nevertheless, differences were encountered regarding co-parenting and general adjustment to divorce. Concretely, parents who had shared custody were those who indicated higher levels of coparenting and divorce adjustment. These results indicate that both types of custody might be linked to comparable psychological functioning for both children and parents. Complementary, these results pinpoint that custody assignments could be related to differential divorce adjustment that could influence parents and children long-term adaptation.
\end{abstract}

Keywords: Custody, parenting style, psychological symptoms, divorce, co-parenting.

\section{Introduction}

The number of divorces increased in the 60s-70s linked to their legalization and, nowadays, data show a similar reality (OECD Family Database, 2018). Besides, more than $60 \%$ of these couples have children (OECD Family Database, 2018). This noteworthy prevalence is very important since divorce circumstances imply demanding stressful life changes that can negatively affect children and parents (v.g. Amato, 2000; Haimi \& Lerner, 2016; Kiecolt-Glaser, 2018; Sbarra, 2015). In this context, societies have evolved and adapted their legal procedures to give solutions focused on setting the best conditions for children. In fact, current research keeps on the need of further evidence about the implications of custody arrangements (v.g. Nielsen, 2017).

The most frequent custody arrangements are exclusive and shared (Utrera, 2009). Exclusive custody implies that children cohabitate with one parent while the other parent has limited fixed contact/visiting periods. Besides, shared custody implies a more balanced cohabitation for both parents and more flexibility on the contact/periods. Therefore, shared custody can have multiple shapes depending on the cohabitation period with each parent (Utrera, 2009).

The existing literature about the benefits of each custody type supports both types of arrangements and there are no clear recommendations (Braver \& Votruba, 2018). Even so, previous research seems to pinpoint towards specific conditions that may explain the differential benefit of shared or exclusive custody. Concretely, the presence of parental conflict and co-parenting are key aspects (Nielsen, 2017). At this regard, children would not benefit from shared custody if their parents have high conflict levels or parents show low cooperation on their parenting responsibilities (Fabricius, Aaron, Akins, Assini, \& McElroy, 2018; Fernández-Rasines, 2017). This can be even more important in high conflict families (Zumbach, 2016). Moreover, authors as Nielsen (2017) indicate that co-parenting can be especially important in high interparental conflict conditions since it would allow to preserve parent-children relationships with both parents. 


\section{Objective}

Based on the exposed, the objective of this study is to examine the characteristics of children and parents who go through divorce depending on the custody type. Concretely, we aimed to test de differences on children psychological symptoms (i.e. somatization, anxiety/depression, and aggressiveness), parents' psychological symptoms, parenting styles (i.e. inductive, indulgent and strict parenting styles), adaptation to divorce and co-parenting by custody type (i.e. exclusive and shared custody).

\section{Method}

A cross-sectional study was developed in Spain directed to divorced parents who attended to public centers that specially give support in high interparental conflict situations.

\subsection{Sample}

The sample was 254 parents (39\% fathers, $61 \%$ mothers) who ranged between 23 to 63 years old. Participants had been married for 10.57 years on average $(\mathrm{SD}=6.36)$ and more than three $(52 \%)$, two $(13 \%)$ or one years $(19 \%)$ had been passed from divorce. They were mostly parents of one or two children $(90 \%)$.

The great majority of parents had the exclusive custody of their children (80\%). In fact, court cases rule predominantly on exclusive custody (60\%). In fact, exclusive custody arrangements were solved mainly after legal dispute (64\% of the exclusive custody cases) while shared custody arrangements were achieved mainly by mutual agreement ( $61 \%$ of the shared custody cases).

\subsection{Scales}

Children somatization, anxiety/depression and aggressive symptoms. Children symptomatology was informed by the parents through the Spanish version of the Child Behavior Checklist (CBCL; Achenbach, 1991). This measure assesses the prevalence of specific symptoms in children. Specifically, we asked participants about children somatization, anxiety/depression and aggressiveness. Answers were recruited on a 3-point Likert scale $(0=$ Not true $-2=$ Usually true $)$.

Parents' psychological symptoms. We measured parents' symptoms by the Spanish adaptation of the Symptoms Checklist (SCL-90; González de Rivera, De las Cuevas, Rodríguez, \& Rodríguez, 2002). Parents were asked how often they felt signs of somatization, interpersonal sensitivity, depression, and anxiety. Answers were recruited in 5-point Likert scales $(0=$ Nothing at all $-5=\mathrm{A}$ lot $)$.

Parenting style. We measured the parenting styles using the Rules-Demands Scale (Bersabé, Fuentes, \& Motrico, 2001). This scale evaluates three parenting styles (i.e. inductive, strict and indulgent styles) concerning the way obedience to rules is established and commanded. Answers were requested on a 5-point Likert scale ( 1 = never -5 = always $)$.

Adjustment to divorce. This variable was measure through the CAD-S (Yárnoz-Yaben \& Comino, 2010). This instrument measures both, parents' adaptation to their new parental commitments versus the general maladjustment described as psychological difficulties of parents to assume the break up, interparental conflict and the socioeconomic impact of divorce. This measure was answered on a

Co-parenting. This variable was measure through the eight items $(1=$ Totally disagree 5 = totally agree) of the CARE questionnaire (Yárnoz-Yaben, 2010). This scale assesses the perception that divorced parents have regarding their ex-partner commitment with their parental responsibilities.

\section{Results}

We developed t-test comparisons in order to examine the differences between the custody groups (i.e. shared and exclusive custody). Results are displayed in Table 1. Regarding children symptoms, t-test indicated that both custody groups reported similar levels of children's somatization, anxiety/depression and aggressive symptoms. Regarding parents' psychological symptoms, results showed that there were no significant differences between both study groups. Likewise, both groups reported similar parenting styles (i.e. inductive, indulgent and strict parenting styles).

Oppositely, both groups differed on adjustment to divorce and co-parenting. Concretely, the shared custody group reported higher levels of both, divorce adjustment to divorce and co-parenting, than the exclusive custody group. 
Table 1. Means, Standard Deviations and Comparisons between Exclusive and Shared Custody Groups.

\begin{tabular}{|c|c|c|c|c|c|c|c|}
\hline \multirow[b]{2}{*}{ Outcome variable } & \multicolumn{2}{|c|}{$\begin{array}{l}\text { Total sample } \\
\quad(\mathrm{n}=254)\end{array}$} & \multicolumn{2}{|c|}{$\begin{array}{l}\text { Shared } \\
\text { custody } \\
(\mathrm{n}=52)\end{array}$} & \multicolumn{2}{|c|}{$\begin{array}{l}\text { Exclusive } \\
\text { custody } \\
(\mathrm{n}=202)\end{array}$} & \multirow[b]{2}{*}{ t-test } \\
\hline & $\mathrm{M}$ & SD & $\mathrm{M}$ & SD & $\mathrm{M}$ & SD & \\
\hline Children somatization & 2.73 & 3.17 & 2.33 & 2.68 & 2.83 & 3.29 & 1.02 \\
\hline Children anxiety/depression & 4.66 & 4.15 & 3.73 & 3.32 & 4.90 & 4.32 & 1.82 \\
\hline Children aggressiveness & 8.99 & 6.92 & 7.71 & 6.57 & 9.32 & 6.98 & 1.50 \\
\hline Parents' psychological symptoms & 38.16 & 32.86 & 38.32 & 35.18 & 38.12 & 32.33 & -0.04 \\
\hline Inductive parenting style & 43.83 & 5.41 & 43.58 & 5.73 & 43.90 & 5.34 & 0.38 \\
\hline Indulgent parenting style & 13.77 & 4.16 & 13.27 & 3.98 & 13.90 & 4.21 & 0.97 \\
\hline Strict parenting style & 23.48 & 6.68 & 22.73 & 5.91 & 23.67 & 6.87 & 0.90 \\
\hline Adjustment to divorce & -0.23 & 1.22 & 0.18 & 1.45 & -0.33 & 1.13 & $-2.74 * *$ \\
\hline Co-parenting & 2.18 & 0.96 & 2.63 & 1.20 & 2.07 & 0.86 & $-3.85 * * *$ \\
\hline
\end{tabular}

Note. t-test compared exclusive custody vs. shared custody.

$* * p<.01, * * * p<.001$

\section{Discussion}

The present research approach the study of parent and children's characteristics after divorce by custody type. Our results indicate that high conflict divorces seem to influence similarly parents' and children's psychological symptoms irrespectively of the custody arrangements. Moreover, parents showed similar parenting styles irrespectively of the custody type. However, exclusive and shared custody arrangements differed on the prevalence of adjustment to divorce and co-parenting. Concretely, shared custody was related to higher adjustment and coparenting after divorce.

These results have two main implications. First, the similar values on parenting and parents and children's psychological symptoms may indicate that both custody types, exclusive and shared, could lead towards positive outcomes. This would explain that both custody types found previous empirical support (vg. Nielsen, 2017). Moreover, this imply that custody arrangements cannot determine the family members' health and that parents can equally exert their parenting capabilities.

Second, shared and exclusive custody groups differed on adaptation to divorce and co-parenting. Thus, parents on the shared custody group had better adjustment to the divorce demands and greater commitment to their responsibilities. This highlights that, to have the same benefits on psychological health, families with shared custody need a better divorce adjustment and higher involvement of both parents on children care. These results is in line with previous concerns about setting shared custody arrangements despite taking into account parents equal involvement on children's care (Fernández-Rasines, 2017) and family adjustment (Parkinson, 2018).

The main limitations of this research are its correlation nature and that only parents participate. Future studies may direct their efforts towards longitudinal with parent and children participants. Moreover, future research could deepen on the understanding of divorce profiles by custody type. Concretely, what happens when parents who have shared custody arrangements are not adjusted to divorce and have low co-parenting levels?

\section{Conclusions}

Custody arrangements define family structures and influence the relationships between the family members. We observed that exclusive and shared custody might lead to similar psychological symptoms of parents and children, but on different conditions. Specifically, shared custody leads to similar psychological adjustment but from higher adaptation to divorce and higher co-parenting than exclusive custody. This fact highlights the need of being cautious and considering family situations before suggesting shared custody in high conflict families to promote parents and children's health after divorce.

\section{References}

Achenbach, T. M. (1991). Manual for the child behavior checklist (4-18) and 1991 profile. Burlington, VT: University of Vermont, Department of Psychiatry.

Amato, P. R. (2000). The consequences of divorce for adults and children. Journal of Marriage and Family, 62(4), 1269-1287. https://doi.org/10.1111/j.1741-3737.2000.01269.x 
Bersabé, R., Fuentes, M. J., \& Motrico, E. (2001). Análisis psicométrico de dos escalas para evaluar estilos educativos parentales. Psicothema, 13(4), 678-684. Retrieved from https://dialnet.unirioja.es/servlet/articulo?codigo=2007083\&info=resumen\&idioma=SPA

Braver, S. L., \& Votruba, A. M. (2018). Does joint physical custody “cause” children's better outcomes? Journal of Divorce and Remarriage, 59(5), 452-468. https://doi.org/10.1080/10502556.2018.1454203

Fabricius, W. V., Aaron, M., Akins, F. R., Assini, J. J., \& McElroy, T. (2018). What happens when there is presumptive 50/50 parenting time? An evaluation of arizona's new child custody statute. Journal of Divorce and Remarriage, 59(5), 414-428. https://doi.org/10.1080/10502556.2018.1454196

Fernández-Rasines, P. (2017). Sharing child custody: Co-parenting after divorce in Spain. Oñati Socio-Legal Series [Online], 7(6), 1229-1246.

González de Rivera, J. L., De las Cuevas, C., Rodríguez, M., \& Rodríguez, F. (2002). Cuestionario de 90 síntomas SCL-90-R de Derogatis, Adaptación española. Madrid: TEA Ediciones.

Haimi, M., \& Lerner, A. (2016). The impact of parental separation and divorce on the health status of children, and the ways to improve it. Journal of Clinical \& Medical Genomics, 4(1), 1-7. https://doi.org/10.4172/2472-128X.1000137

Kiecolt-Glaser, J. K. (2018). Marriage, divorce, and the immune system. American Psychologist, 73(9), 1098-1108. https://doi.org/10.1037/amp0000388

Nielsen, L. (2017). Re-examining the research on parental conflict, coparenting, and custody arrangements. Psychology, Public Policy, and Law, 23(2), 211-231. https://doi.org/10.1037/law0000109

OECD Family Database. (2018). SF3.1: Marriage and divorce rates. Retrieved from http://www.oecd.org/els/family/database.htm

Parkinson, P. (2018). Shared physical custody: What can we learn from Australian law reform? Journal of Divorce and Remarriage, 59(5), 401-413. https://doi.org/10.1080/10502556.2018.1454197

Sbarra, D. A. (2015). Divorce and health. Psychosomatic Medicine, 77(3), 227-236. https://doi.org/10.1097/PSY.0000000000000168

Utrera, J. L. (2009). Guía básica para un buen divorcio. Barcelona: Ediciones B, S. A.

Yárnoz-Yaben, S. (2010). Cuestionario de Apoyo Recibido de la Ex pareja (CARE): Un instrumento breve paraevaluar la co-parentalidad post divorcio. Revista de Psicopatología y Psicología Clínica, 15(2), 133-142. https://doi.org/10.5944/rppc.vol.15.num.2.2010.4092

Yárnoz-Yaben, S., \& Comino, P. (2010). El CAD-S, un instrumento para la evaluación de la adaptación al divorcio-separación. Psicothema, 22(1), 157-162.

Zumbach, J. (2016). Mental disorders in children and parents in family law proceedings: Cases on child protection matters versus child custody and visitation issues. Journal of Child and Family Studies, 25(10), 3097-3108. https://doi.org/10.1007/s10826-016-0476-8 